Mick Healey, HEALEY HE CONSULTANTS, mhealey@glos.ac.uk

Kelly E. Matthews, UNIVERSITY OF QUEENSLAND, k.matthews1@uq.edu.au

Alison Cook-Sather, BRYN MAWR COLLEGE, acooksat@brynmawr.edu

\title{
Writing Scholarship of Teaching and Learning Articles for Peer-Reviewed Journals
}

\begin{abstract}
There are many general books and articles on publishing in peer-reviewed journals, but few specifically address issues around writing for journals focused on the Scholarship of Teaching and Learning (SoTL). One of the challenges of beginning to write about teaching and learning is that most scholars have become interested in exploring these issues in higher education alongside their disciplinary interests and have to grapple with a new literature and sometimes unfamiliar methods and genres, as well. Hence, for many, as they write about their projects, they are simultaneously forging their identities as scholars of teaching and learning. We discuss the process of producing four types of SoTL-focused writing for peer-reviewed journals: empirical research articles, conceptual articles, reflective essays, and opinion pieces. Our goal is to support both new and experienced scholars of teaching and teaching faculty/academics, professional staff, and students - as they nurture and further develop their voices and their identities as scholars of teaching and learning and strive to contribute to the enhancement of learning and teaching in higher education. We pose three related sets of overarching questions for consideration when writing about teaching and learning for peerreviewed journals and offer heuristic frameworks for publishing in the four specific writing genres listed above. We also discuss how to get started with writing, preparing to submit, and responding to reviewers, focusing on the importance of contributing to and creating scholarly conversations about teaching and learning. Finally, using the metaphor of being in conversation, we argue that writing is a values-based process that contributes to the identity formation of scholars of teaching and learning and their sense of belonging within the SoTL discourse community.
\end{abstract}

\section{KEYWORDS}

academic journal writing, SoTL identity, empirical research articles, conceptual articles, reflective essays, opinion pieces

\section{INTRODUCTION}

There is growing acknowledgement that we ought to learn more about writing if we want to be published in academic journals.

—Rowena Murray, Writing for academic journals (2009, p. 3)

Thankfully, many general books about publishing in peer-reviewed journals have been produced over the last ten years (e.g., Belcher, 2009; Day, 2016; Rocco \& Hatcher, 2011). However, in terms of 
publishing scholarship about teaching and learning, as Chick, Cornell-Swanson, Lazarides, and Meyers (2014, p. 4) note, "There are distinct issues in SoTL writing and publishing that remain unaddressed in generic or disciplinary publication materials." Moreover, most writing guides target $\mathrm{PhD}$ students publishing from their dissertations (e.g., Kamler \& Thomson, 2014), whereas the audience for a SoTLfocused publishing guide is mainly scholars (faculty/academics and students) relatively new to writing about SoTL (Sadler, 2006).

One of the challenges most scholars face when beginning to write about teaching and learning is that they have become interested in exploring issues in higher education alongside their disciplinary interests. They therefore have to grapple with a new literature and sometimes unfamiliar methods and genres, as well, and as they write about their projects, they are simultaneously forging their identities within this field. While some might resolve this tension by exploring SoTL-focused topics within their disciplinary context and seeking publication in disciplinary teaching and learning journals (Healey \& Jenkins, 2003), others will want to go on and publish in cross-disciplinary SoTL-focused journals, such as Teaching \& Learning Inquiry (TLI), where they will need to place their work in the context of a broader literature and address the interests of a wider audience. We argue that writing is an integral part of, not separate from, developing an identity as a scholar of teaching and learning.

As the authors of this article, we share an interest in scholarship about teaching and learning in higher education, and particularly in partnerships among students, faculty/academics, and others in learning and teaching. We currently work together as three of the founding co-editors of the International Journal for Students as Partners (IJSaP). However, our formative experiences of SoTL are influenced by having worked in three different disciplinary contexts and on three different continents. Moreover, we have varied lengths of experience working in the SoTL arena and distinct approaches to academic writing. We include some background on our development as SoTL scholars (see text box 1). Since both our shared and our diverse identities as scholars of teaching and learning inform our arguments, we use a collective $w e$ for most of this discussion, but we also integrate our own words (see text boxes $1,2,8,10,11)$. Our intent is for our respective voices to surface our different experiences and views to illustrate our argument that there is no one way to write about teaching and learning or to be a "SoTL writer."

\section{Text box 1. In our own words: Our development as scholars of teaching and learning}

Mick: I come from a disciplinary approach to SoTL. After more than a decade researching and writing about economic geography, my first SoTL-focused publication developed from a reorganization of our first-year practical classes in geography at Coventry University in the United Kingdom in the late 1980s. It was only after winning a National Teaching Fellowship in 2000 (through which what is now Advance HE in the United Kingdom recognizes outstanding impacts on student outcomes and the teaching profession in higher education), more than a decade after my first pedagogic publication, that I began to write more generally about SoTL-focused issues. My maturity as a scholar of teaching and learning grew through engagement with the International Society for the Scholarship of Learning and Teaching (ISSOTL) and co-editing the International Journal for Academic Development.

Kelly: My first publications arose from an undergraduate research position in a biomedical science laboratory before I started teaching science in New Orleans, in the United States. I moved to Australia in 2006. Working at a large, comprehensive, research-intensive university, the University of Queensland, I saw that publishing 
was an essential currency. Two years later the university adopted a policy that created a new classification of
academics who researched and published Scholarship of Teaching and Learning. Not only did I begin writing
in the field of SoTL, but in the university's centralized teaching and learning unit, a key part of my role was
supporting teaching-focused academics in publishing their SoTL-focused work. Working in that role, while
completing my PhD (2008-2014) on students' perspectives of learning, offered me tremendous
opportunities to engage in research and academic writing.
Alison: My background is in education. After teaching high school English in California for a number of years, I
completed a PhD in education and assumed leadership of the secondary teacher certification program at Bryn
Mawr and Haverford Colleges in the United States. My early publications in the 1990s focused on teacher
education and, in particular, secondary students' roles and voices in teacher preparation. In the early 2000s, I
started to assume more responsibility for educational development and I brought the focus of student-teacher
partnership to that work. The Students as Learners and Teachers program I developed became
internationally known and emulated, and as I started publishing work on that program, I came into contact
with scholars and practitioners who were also interested in student voices and participation in educational
development.

To ground our discussion of developing an identity as a scholar of teaching and learning and producing writing for SoTL-focused publications, we provide an overview of four genres of SoTL writing for publication in refereed journals: empirical research articles, conceptual articles, reflective essays, and opinion pieces. We recognize that refereed journal publication is not the only way to "go public" with writing about teaching and learning: writing for local publications, posters, or blogsites is also influential for authors and the field. Our focus, though, is on questions to address when aiming to publish in peer-reviewed journals.

After this overview, we explore the relationship between writing and developing an identity as a scholar of teaching and learning and develop the argument that writing is always a value-based practice. Our goal is to support both new and experienced scholars in this field as they nurture and further develop their voices and their identities and strive to contribute to the enhancement of learning and teaching in higher education. We recognize, though, that there is no one way to write successfully for publication and, like some colleagues (e.g., Thomson \& Kamler, 2013; Sword, 2016), we are skeptical of best-practice guides that emphasize a single approach that implies any other way is deviant or inferior. Therefore, we pose three related sets of overarching questions for consideration when writing SoTL pieces for peer-reviewed journals: How can you use writing in SoTL? What opportunities does SoTL writing afford you? How might you embrace the potential of SoTL writing?

To support the production of writing for the types of SoTL-related publications upon which we focus, we offer heuristic frameworks for publishing in the four genres we noted above. Although we attempt to tease out some of the distinct characteristics of the various genres, we also want to disrupt the conventional wisdom that they are entirely different. In this article, we deliberately mix the styles associated with the different genres by engaging in a scholarly discourse in some places; providing a guide to alternative practices in other places; and including our personal and often contrasting reflections in text boxes labeled "In our own words" alongside what the literature says. Finally, we discuss how to get started with writing, preparing to submit, and responding to reviewers, focusing on the importance of contributing to and creating conversations about teaching and learning. In an effort both

30 Healey, M., Matthews, K.E., \& Cook-Sather, A. (2019). Writing Scholarship of Teaching and Learning articles for peer-reviewed journals. Teaching \& Learning Inquiry, 7(2).

http://dx.doi.org/10.20343/teachlearninqu.7.2.3 
to demonstrate and to raise awareness regarding the effect of different modes of address, we write not only in the third person, as in the opening few paragraphs above, but also in the first person (singular and plural) when speaking from our perspectives, and in second person when addressing readers directly. We also refer to ourselves and each other by our first names.

\section{DIFFERENT GENRES FOR PUBLISHING IN PEER-REVIEWED JOURNALS}

Given that the field of SoTL is a broad tent (Huber \& Hutchings, 2005), most SoTL-focused journals welcome a wide variety of genres. For example, TLI states that it accepts submissions that are "[p]ieces documenting completed SoTL projects, theoretical or scholarly essays, systematic reflections, syntheses of literature, or reports on the field" (TLI, n.d.). Other journals have separate sections for different genres. For example, IJSaP has separate sections for research articles, case studies, reflective essays, opinion pieces, and reviews. In a workshop that Chick and Felten (2018) ran at ISSOTL18 they emphasized the importance of recognizing a wide range of genres:

The practice of SoTL ... necessarily involves simplifying complex, messy, and personal experiences into a presentation, article, or other genre that appears conclusive, tidy, and comprehensible. In this session, we will co-create with participants examples of a new SoTL genre: true stories. (p. 193)

We feel it is important to name different genres to give permission to authors to write in different styles. Some journals use identical criteria for assessing articles regardless of genre; for example, they ask questions about the appropriateness of the methods, which unfortunately implies that all SoTLfocused writing is reporting empirical research. Kelly recently submitted a reflective essay to one such journal (not TLI) and one of the reviewers recommended rejection because " $\mathrm{t}]$ here is no clear methodology. The empirical material that was provided is very poor. It is not enough to support any argument. There are no clear conclusions." To avoid this kind of confusion we think that naming genres explicitly and clarifying the distinctions and overlaps between and among them is helpful and encourages a diversity of submissions.

For the purposes of this article, we focus on four genres: empirical research articles, conceptual articles, reflective essays, and opinion pieces. (We include discussion of other genres in the book we are writing [Healey, Matthews, \& Cook-Sather, in press]). The boundaries between the genres are porous, but there are also important distinctions.

Empirical research articles are the most common genre for SoTL-focused publications. They encompass what many of us would call traditional research, whereby data (e.g., from interviews, surveys, document analyses, reflections, and narratives) are gathered to offer evidence for a particular aim or in response to a research question. Research articles typically include an introduction, a literature review, sections on methods, findings, discussion, and implications, and a conclusion.

Unlike empirical research articles, the conceptual article genre typically does not involve the collection of data. Instead, existing literature and established theories are explored and the approach or method for the conceptual analysis is articulated for readers. The format of conceptual articles will look different from that of a research article, too; rather than include the sections listed above under empirical research articles, conceptual pieces draw on literature to build an argument in order to provoke, deepen, or expand thinking. 
Reflective essays invite authors to share the messy, unfinished, personal work of SoTL-the lived experience and the sense people make of it that rarely find a place in other forms of scholarship. Writing a reflective essay therefore requires a mindset and style that differ from both empirical research and conceptual articles (Cook-Sather, Abbot, \& Felten, 2019): willingness to share in-process experiences and insights, write in the first person, and present learnings rather than empirical findings or arguments.

Opinion pieces afford authors an opportunity to assert a value judgment about teaching and learning based on considered experience and informed perspective. Unlike a reflective essay that aims to share lived experiences and resulting insights, opinion pieces aim to argue for and convince readers of a particular perspective. Such pieces need not draw on data sets or bodies of literature (as empirical research and conceptual pieces, respectively, must), but they do need to be situated in ongoing conversations in the field.

These distinctions among the genres are not hard and fast. However, we offer the general descriptions above to help you decide which genre is most conducive to the SoTL story you want to tell at any given moment and the identity you want to develop as a scholar of teaching and learning.

\section{SOTL IDENTITY AND COMMUNITY BUILDING THROUGH WRITING \\ Fostering a SoTL identity through writing}

Writing is an essential form of communication for scholars. Indeed, the typical rite of passage into the academy is marked by completion of a thesis or dissertation through which one formally joins the conversation in one's field. Joining the broad tent (Huber \& Hutchings, 2005) of SoTL, initially inspired by Boyer (1990), differs somewhat.

Healey (2003) suggests that SoTL is widely recognized to mean

- engagement with the scholarly contributions of others on teaching and learning;

- reflection on one's own teaching practice and the learning of students within the context of a particular discipline;

- communication and dissemination of aspects of practice and theoretical ideas about teaching and learning in general and teaching and learning within the discipline.

(Martin, Benjamin, Prosser, \& Trigwell, 1999, p. 327)

This field of scholarship brings teaching into a shared public space where a community can reflect and learn together, as is the common practice with research (Shulman, 1999). While "going public" with one's scholarship about teaching and learning includes participating in local conversations or making conference presentations, writing for publication is a key form of communication. Yet, many scholars of teaching and learning do not have formal training in writing in or for the field. Although many are published writers in their disciplines, they enter SoTL from a different discipline (Healey, 2000). Therefore, many scholars of teaching and learning are dual citizens, part of two discourse communities, each with distinct customs and cultural norms, although both privilege writing as a form of currency, esteem, and communication.

The challenge of being a disciplinary scholar and SoTL scholar has been a continuing discussion in the literature. For example, Miller-Young, Yeo, and Manarin (2018) argue that coming to SoTL causes a type of epistemological dissonance that is problematic and troublesome for faculty/academics from a range of disciplines who "experienced a disruption in their sense of identity, causing them to 
question themselves as a teacher, researcher and colleague" (p. 4). Even educational developers, who are at the forefront of encouraging scholarship focused on teaching and learning, can also find it difficult to make sense of new research expectations in a different discipline (Little, Green, \& Hoption, 2018).

Emphasizing the positive potential of this challenge, Simmons et al. (2013) suggest that "SoTL serves as a location for integrating multiple, conflicting, and interdisciplinary areas of academic work" (p. 18). They assert that an international collaborative writing group initiative enabled a diverse range of scholars of teaching and learning to develop their capacity for writing through collaborating on a SoTLfocused journal article; the group offered "an invitation to further conversations" (Simmons et al., 2013, p. 18) that nurtured their identities as SoTL scholars.

We agree that writing shapes our identities as scholars. We think of identity as the way in which "individuals define and experience themselves and are defined by others-how an individual/personal sense of sociocultural location and character intersects with how that individual is constructed in many different ways within any given culture and society" (Cook-Sather, 2015, p. 2). We include some reflections on how our identities as writers have shaped how we have developed identities as scholars of teaching and learning (text box 2).

\section{Text box 2. In our own words: How we see ourselves as writers}

Mick: I do not find writing easy. Whatever I write for publication goes through many drafts, as I don't know what I think until I start to write. I have become more reflective and personal in my writing as my identity as a scholar of teaching and learning has developed.

Kelly: I have always struggled with writing. My relationship with writing is tricky and entangled with who I am. I bring that baggage to my scholarship on teaching and learning work. Luckily, the SoTL community is open about difficulties in writing, which is inviting and affirming.

Alison: I have always loved writing, and it comes very easily to me. That doesn't mean that I write one draft and am done. Ever. But it means that expanding my identity as a writer to encompass SoTL-focused writing does not feel like an uncomfortable stretch.

Because writing for SoTL is entangled with how we see ourselves as writers and as scholars of teaching and learning and how we relate to and are perceived by the discourse community, talking about identity formation matters when we talk about writing in this field. Writing is a scholar's way of being in the conversation and making that attempt for the first time or seeking to contribute to the conversation in a different way or to create new conversations is both intellectual and emotional work. To put ourselves out there for potential rejection or misinterpretation is to experience vulnerability, yet also provokes the excitement and joy that arises from the courage to try something new. As Kamler and Thomson (Kamler \& Thomson, 2014; Thomson \& Kamler, 2013) argue, academic writing of any type is identity work as much as it is text work. Writing shapes the writer as much as the writer shapes their writing.

The differing disciplinary standpoints and methodological pluralism that characterize SoTL is a strength (Chick \& Poole, 2013); our diversity is a resource (Cook-Sather, 2015) that contributes to our evolution as scholars of teaching and learning and to what is welcomed under the big tent of SoTL. While research or design might follow established and appropriate approaches for SoTL (Felten, 2013) 
that embrace pluralism, writing is a human, subjective, personal process of communicating with peers, shaping how authors see themselves in the SoTL community. For these reasons, we conceptualize writing as a process of identity formation and of developing a sense of belonging to the SoTL discourse community.

\section{Writing as a values-based practice}

Expanding on Kamler and Thomson's idea of "work" in writing (Kamler \& Thomson, 2014; Thomson \& Kamler, 2013), we believe that writing is also "values work." Every author, whether consciously aware of it or not, considers particular approaches, styles, and standards of writing to be important. As readers, we also bring assumptions about what is important and appropriate in writing. Often, we adopt approaches to writing without even thinking about the values underlying that approach. For example, writing in the third person, which is common practice, particularly in the sciences, values distance between the writer and the written work. Thus, how we write and read written text is inextricably intertwined with our values.

In academia, our values tend to be aligned with our disciplinary communities and often reveal themselves when we begin to write about teaching and learning. Instead of lamenting the lack of a single, uniform way of writing about teaching and learning, we celebrate the range of disciplinary approaches brought to bear. Publishing in the field of SoTL is about people in a particular context where the scholar is typically a practitioner with insider knowledge and insights. To share our values explicitly and to invite you to consider yours, we offer a broad set of interrelated questions regarding becoming a scholar who writes about teaching and learning, recognizing the opportunities writing for this field affords, and embracing the potential of writing about teaching and learning (text box 3 ).

\section{Text box 3: Considering your values in writing about teaching and learning}

(1) How can you use writing about teaching and learning to

(a) shape your identity and nurture your sense of belonging within the SoTL discourse community?

(b) be present in your writing and express yourself with a clear voice?

(c) engage both emotionally and intellectually?

(2) What opportunities does SoTL writing afford you to

(a) inquire into the complexities of teaching (and learning) and of students' experiences of learning (and teaching)?

(b) participate in ongoing conversations or create new ones within the SoTL discourse community?

(c) push "conventional boundaries" within the discourse community by drawing on your disciplinary expertise and/or embracing a methodological pluralism?

(3) How might you embrace the potential of writing about teaching and learning to

(a) acknowledge, affirm, and constructively critique rather than attack or undermine?

(b) illuminate and expand, rather than obscure or diminish?

(c) represent context-specific complexity well, rather than reduce to generalizable simplicity? (Poole, 2013) 
SoTL-focused publications embrace diverse forms and styles of writing, and we include that diversity in our discussion of publishing on teaching and learning. In our collective experience, no stepby-step guide for publishing has removed the need for the hard, emotional, and intellectual work that academic writing involves, the unique way each person approaches this work, and the context-specific nature of the scholarship that writing for this field needs to represent (Healey \& Healey, 2018; Poole, 2013). But having frameworks and guidelines helps.

\section{HEURISTIC FRAMEWORKS FOR DIFFERENT GENRES FOR PUBLISHING IN PEER-REVIEWED JOURNALS}

The heuristic frameworks below are meant to provide questions to explore and guide writing. The frameworks are not intended to be perfect or prescriptive but rather to offer steps for getting started by presenting questions for consideration. Our expectation is that you will employ these heuristic frameworks creatively, in ways that make sense for you.

Each framework consists of a set of questions. Not every question has to be answered, or taken up in the order displayed, and, depending on the story you want to tell, we suspect you will think of other questions that should be addressed in your publication. Mick and Kelly's experience of using some of these heuristic frameworks in workshops suggests that participants find them helpful to plan what they want to include, establish the flow of the publication, and find a focus. Figure 1 offers a potential process from selecting your genre to publishing using our heuristic frameworks. However, we encourage you to change the order, add, remove, or repeat parts of the process (see also Grant, 2016).

Figure 1. Process for employing the heuristic frameworks for writing for publication

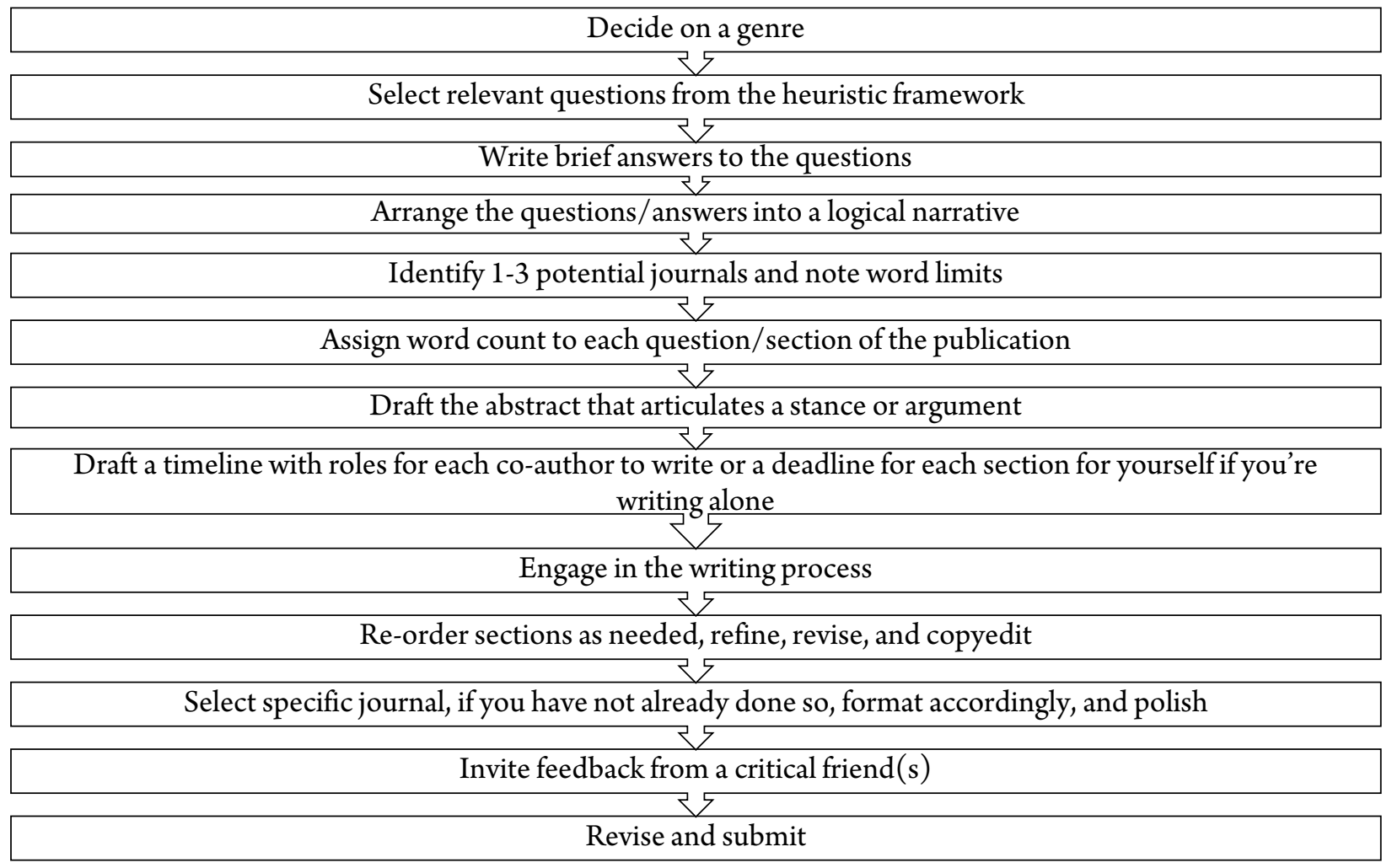


There are some commonly accepted criteria that apply to all genres. These often take the form of statements, for example, that a submission must

- address the interests of the journal's intended audience (be in the conversation of the journal);

- be clear, concise, complete, well written, high quality, and accessible to the journal's readership;

- not have been previously published or currently in submission with another journal; and

- meet the journal's format and style guidelines.

Whatever the genre, the submission must contribute to the ongoing conversation or endeavor to create a new one by offering some new perspective or insight that expands thinking within the discourse community. Along with depth of contribution, also consider your style of writing to communicate your ideas in a clear and interesting manner (Sword, 2012).

\section{Empirical research articles: Analyzing and reporting data to advance SoTL}

Empirical research articles should provide a clear rationale for the study situated within a body of published research, an overview of the research methodology used, an analysis of findings, and a discussion of those findings and their implications in relation to existing knowledge. SoTL-focused inquiry typically captures data from classroom practices that are presented as case studies grounded in context-specific detail (Chick \& Poole, 2018). These tend to be scholarly explorations of specific practices, examples, or initiatives that could be either continuing or one-off projects. However, simply describing the classroom practice and reporting data are insufficient for this genre, which requires interpretation of data with broader implications linked to the SoTL literature. In other words, empirical research articles have to acknowledge the current SoTL conversation and extend or expand it through the conduct of primary research. Drawing on Kinash and Wood (2012) and Thomson and Kamler (2013), we offer a series of questions to support the writing of empirical research in SoTL (text box 4).

\section{Text box 4. Heuristic framework of guiding questions to support planning, revising, and refining of an empirical research article for SoTL-focused publication}

1. Why is this topic important in SoTL, to whom, and why at this time?

2. What previous research has been undertaken on this topic? What is your contribution to the literature/SoTL conversation?

3. What is your argument or stance? What question(s) are you addressing?

4. What is your underlying conceptual or theoretical framework? If appropriate, what is (are) your hypothesis(es)?

5. What are your research methods and what is the rationale for your approach?

(a) What data have you collected, and how?

(b) Who are your participants?

(c) What is the context (e.g., discipline, institution, nation)?

6. How have you analyzed the data?

7. What are your findings and how do they contribute to or expand the ongoing SoTL conversation?

8. How do your findings compare with previous research?

9. How do you handle/present unexpected findings?

10. How does the context influence your findings? What are the implications for others in different contexts? 
11. What are the limitations of your research? What unanswered questions remain? What other questions follow for future research on teaching and learning?

Most of the articles published by TLI fit in this genre. Recent examples include an Australian analysis of students' perceptions of their learning outcomes, engagement, and satisfaction with a technology-facilitated flipped approach in a core course in entrepreneurship (Fisher, Ross, LaFerriere, \& Maritz, 2017); a New Zealand study that evaluates and compares approaches to learning by a longitudinal cohort of undergraduate students as they progressed from their first to third years of study in science using the Approaches and Study Skills Inventory for Students (McDonald, Reynolds, Bixley, \& Spronken-Smith (2017); and an analysis of the representations of higher education within 11 topgrossing critically acclaimed films released in 2014, co-authored by two students and a member of faculty in a Canadian university (Johnstone, Marquis, \& Puri, 2018).

\section{Conceptual articles: Offering new perspectives to advance SoTL}

Drawing together existing literature to offer a new perspective or reframe existing theorizations is vital to advancing and expanding the scholarly conversation about teaching and learning. It is common for conceptual articles to dig deeply into the work of a few scholars, representing a specific form of conversation that is strongly grounded in the literature but does not present primary data or test concepts.

Conceptual articles offer the exciting opportunity to productively disrupt the ongoing conversation or to change it completely through the creative analysis of existing works that shape something new. Because of the creativity and deep knowledge of the literature required, conceptual articles tend to take a long time to write. Getting lost in the literature can lead authors to go off on tangents that fragment the work and diminish the argument or stance. We offer a set of questions to guide you toward focused yet rich conceptual articles that provoke new thought and debate within the SoTL discourse community (text box 5).

Text box 5 . Heuristic framework of guiding questions to support planning, revising, and refining of a conceptual article for SoTL-focused publication

1. What is your overall aim and rationale for this article?

2. What does your work contribute to wider field of SoTL?

3. What concepts/theories are you exploring in your article and how do you define them for the purposes of your analysis?

4. How was the analysis conducted?

5. Why and to whom do these concepts/theories matter in teaching and learning?

6. How do scholars discuss and critique these concepts/theories?

7. What new insights or frameworks are you bringing to these concepts/theories?

8. What are the implications of your analysis for researchers and/or practitioners?

9. What further research or actions are prompted by your analysis?

Kreber's (2013) article in TLI is an example of a conceptual article that draws on a theoretical framework to argue for an "extended" stance on issues of teaching and learning linked to social justice. Another example, and one of TLI's most cited publications, is Felten's (2013) principles of good 
practice in SoTL, in which theories from a range of scholars are distilled into five principles for practitioners.

\section{Reflective essays: Revealing lived experiences to advance SoTL}

In writing a reflective essay, you should keep the focus on lived experiences and the sense you made of them - such as what you attempted, struggled with, learned from, or realized. We have found in reviewing submissions of reflective essays for both IJSaP and Teaching and Learning Together in Higher Education, another journal for which Alison serves as editor and in which Kelly has published, that some authors focus too much on subject matter or research outcomes and not enough on the process of their experiences, both positive and negative, and it is those details of lived experience that reflective essays aim to present.

Reflective essays are written as informal, first-person accounts. They show, as opposed to tell, through offering vivid, detailed examples instead of simply stating that something happened. They offer analysis of that lived experience that illuminates the day-to-day practicalities of the work and/or insights gained into the potential of such work in higher education. Such analyses might include offering explanations and interpretations (not assuming examples speak for themselves); making assumptions explicit; clearly articulating insights and conclusions; and making connections across points. Finally, because they focus on lived experience, reflective essays include a small number of citations of existing literature, rather than the extensive number expected in some other genres. We offer a set of questions to help you focus on your lived experiences (text box 6).

\section{Text box 6. Heuristic framework of guiding questions to support planning, revising, and refining of a reflective essay for SoTL-focused publications}

1. What situation, scenario, or event are you reflecting upon?

2. Who is doing the reflection and what are your/their roles in the situation, scenario, or event?

3. What is the broad teaching/learning context of your reflection?

4. What prompted your reflection on this topic or situation?

5. How did you structure your approach to reflection?

6. How can you convey to readers the particulars of your experience rather than assume familiarity with or understanding of how the experience unfolded?

7. What did you learn from the reflection that others can benefit from reading about?

TLI does not have a section designated for reflective essays. This genre is designated, however, in IJSaP. Authors have written reflective essays that "zoom in" on different moments and lived experiences of partnership (Brost, Lauture, Smith, \& Kersten, 2018); detail the launching and development of student-faculty pedagogical partnership programs (Goldsmith, Hanscom, Throop, \& Young, 2017); and unpack the complexities of a collaborative undertaking (Macfarlane, Dennison, Delly, \& Mitric, 2018). With some exceptions for guest-edited issues, Teaching and Learning Together in Higher Education is devoted almost entirely to reflective essays.

\section{Opinion pieces: Provoking thought to advance SoTL}

Opinion pieces are short, focused works intended to provoke thought by typically illuminating a gap, contradiction, opportunity, or inequity within the discourse community. When writing an opinion 
piece, you should state a clear and direct position and then support it with persuasive argument that draws on the literature or your lived experience. Opinion pieces can be difficult for emerging scholars to write because they tap into an ongoing conversation that assumes deep knowledge of the field while also privileging a strong voice from the author. Nevertheless, we would suggest that those new to SoTL, by virtue of being new to the community, offer unique perspectives that remind the established discourse community to be mindful of new voices and to value what they contribute. We encourage new voices in SoTL to proffer opinions, and we offer a heuristic framework to help guide that effort (text box 7).

Text box 7. Heuristic framework of guiding questions to support planning, revising, and refining of an opinion piece for SoTL-focused publications

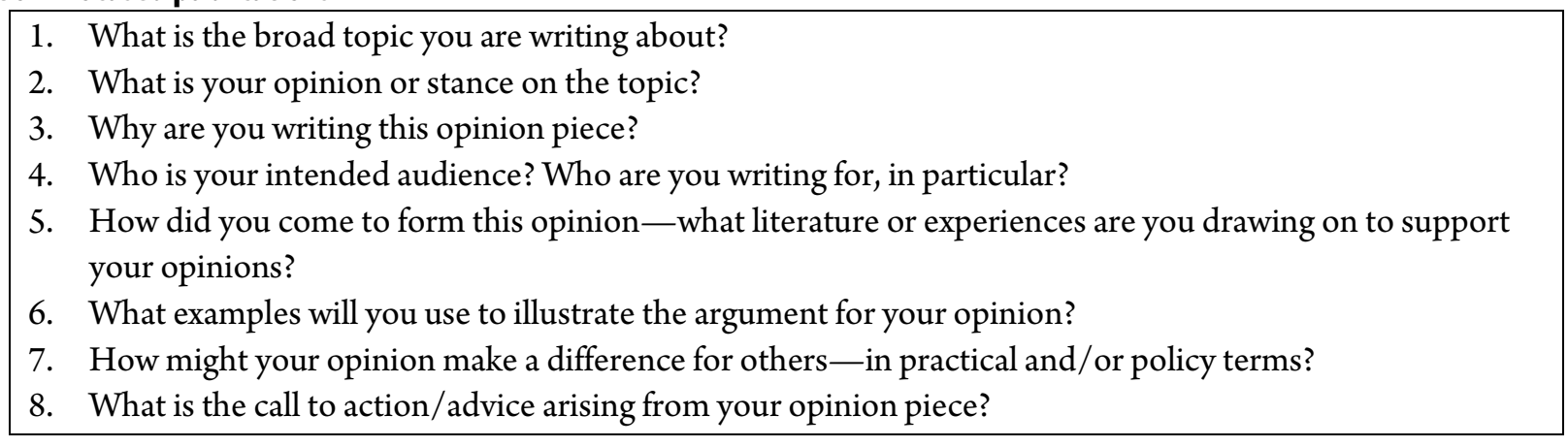

For examples of opinion pieces, we look to IJSaP because it publishes such pieces. A recent issue showcases two opinion pieces on the topic of equity in engaging with students as partners in teaching and learning, one from students in a Canadian university (Bindra et al., 2018) and the other from a staff member in an Australian university (O'Shea, 2018). Again, the lines between genres are blurry. A recent introduction to TLI from the editors, which read like an opinion piece, argued for the value of local and small-scale SoTL research (Chick \& Poole, 2018).

GETTING STARTED WITH YOUR WRITING

Regardless of the genre in which you choose to write, we suggest you consider the following issues.

\section{Writing alone or with others: What is the role of collaboration in writing?}

Less than 20 percent of the articles published in TLI in 2017 and 2018 were written by a single author. Yet many appreciate the independence of writing on their own, and single-authored publications are expected in some disciplines, particularly within the humanities. Writing alone means you can set your own schedule, write at your own pace, and use your own voice. These are all benefits. While most authors will write alone some of the time, writing your first article can be a scary experience. You have to be very determined and self-motivated to complete the task. Finding time and space to write involves self-awareness and intentionality, whether you are just starting out or have a good deal of experience. If you are introverted or appreciate solitude, writing alone can be energizing and efficient. If you are more extroverted and thrive in the company of others, then writing on your own can be a lonely business. One way to both write alone and benefit from others' insights is to join a writing group (Murray, 2009). 
We have all written on our own and with colleagues, which increasingly include students (see text box 8). We have generally found that working with others enables us to cover more ground, is more enjoyable, and has benefitted the quality of the writing (Black, Brown, Day, \& Race, 1998). Sometimes the division of labor can save time. In other situations, especially where there is a large writing team, it can take longer to complete the work, as it involves more negotiation and editing to achieve a unified voice. Deciding on author order for multi-authored text can cause tensions, particularly if there are power relationships between the authors (Maurer, 2017), so it is best to discuss the principles by which authorship will be decided before starting to write and periodically revisit author order throughout the process.

\section{Text box 8: In our own words: Collaboration versus writing solo}

Mick: Whereas when I wrote as an economic geographer, I usually wrote by myself, when I moved into writing, first about geography in higher education and then about teaching and learning more generally, I more commonly co-wrote with colleagues. Collaborating generally made the writing process a much more enjoyable experience and improved the clarity and quality of our writing. I usually learn a tremendous amount from my co-authors, as has happened, for example, in writing this article. The only times collaboration has not worked quite so well was when my co-author(s) had different attitudes from me towards keeping to deadlines and responding in a timely manner to queries. So, choose your co-authors with care!

Kelly: I collaborate a lot-90 percent of my publications are co-authored. The collaborative process is a rich learning process that offers collegiality, connection, and mentorship. However, collaboration can be slower than solo writing and different voices can get lost or overpower others in the process. Increasingly, I co-author with undergraduate students, which has inspired my writing and thinking in new ways. To keep collaborators on the same page and create space for everyone to contribute meaningfully, I usually start new writing projects by outlining some key points (journal, aim, contribution) using one-page pro formas (Matthews, 2018a; 2018b).

Alison: As an introvert and someone to whom writing comes easily, I am perfectly happy to write alone. I have published many single-author pieces. At the same time, I experience collaborative writing as a form of dialogue in practice, and I find that it can invite further dialogue. I am energized by most co-authorship, and I am smarter in collaboration than I am alone. Through writing with others, I am forced to wrestle, grow, reconsider, and compromise, as well as to learn new things and to make explicit what I think I already know. To my mind, co-authoring has a better chance of capturing the multiplicity of perspectives that is virtually always relevant.

Co-authoring is both intellectual and emotional work. One team of three authors who had collaborated for two decades and co-authored more than 35 publications reflected, "In any one session, we learned to expect the unexpected - to be exhilarated and confused, surprised and displeased, praised and pained-sometimes at the same time" (Nevin, Thousand \& Villa, 2011, p. 290). It is also a source of sense of community. International collaborative writing groups have become a signature feature of the International Network for Learning and Teaching Geography in Higher Education and ISSOTL (Healey, 2017). Such collaborative groups can operate as a community of practice (Matthews, Marquis, \& Healey, 2017), in which both the facilitator(s) and the group leader play a critical guiding role. 


\section{Choosing a journal: Whom do you want to talk to?}

Writing about teaching and learning means contributing to ongoing conversations or creating new ones with others in the SoTL community, albeit rather protracted ones with long silences. What you want to contribute to an existing conversation or create anew will affect the genre you choose to write in and to which journal you submit. For example, you might have research results to share that lend themselves to a traditional empirical research article genre, or perhaps you have formed a strong stance based on experience and your research that makes sense to express in an opinion piece. Many authors, when they begin, draft their article first and then choose a journal. However, if you decide on the journal, or possibly two or three suitable journals, before you start writing, you can begin to address the audience to whom the journal is aimed early in your writing (Moore, 2018).

Some journals, such as TLI, the International Journal of Scholarship in Teaching and Learning, and the Canadian Journal for the Scholarship of Teaching and Learning, are specifically aimed at SoTL audiences; others, such as Teaching in Higher Education or Higher Education Research and Development, target those with more general interests in learning, teaching, and research on higher education. Others, such as the Journal of Geography in Higher Education and IJSaP, are more specialist and are aimed at particular SoTL audiences.

One of the most common reasons for editors to reject papers is that the submission is not appropriate for the journal (Noble, 1989). Hence, it is essential that you read the mission statements for the journals you are considering and ask yourself the following questions:

- Is this the group of scholars I want to be in conversation with?

- Will this work contribute to the conversation in this discourse community generate a new conversation?

A good rule of thumb in selecting possible journals for further investigation is to look at the references you propose to use. If you are planning to cite two or three articles recently published in a particular journal, that is a good indication that your submission will address a topic of current interest to that journal. Whatever journal you choose, it is worth browsing through the last half dozen or so issues to see the kind of pieces it publishes, how they are written, and whether you can make linkages to related conversations. Making such linkages shows that you are listening to the relevant discussions, as we have attempted to do here by drawing on several articles previously published in TLI.

We recognize that there are pressures in some institutions to publish in what are perceived as the top journals. This usually means established journals with high citation scores. However, such journals also have high rejection rates. Most journals specializing in SoTL are relatively new and have yet to be ranked as top journals, yet they may be more appropriate outlets to reach the readers you wish to engage. We have each published in a wide range of journals and recommend submitting to a diversity of outlets.

The readership for an international SoTL-focused journal differs from that for a national discipline-based teaching and learning journal. Hence, writing for the former you need to address a transdisciplinary audience who will not necessarily be familiar with disciplinary practices and the structure of higher education in your country (Thomson, 2017). This can be particularly challenging for non-English-speaking authors, but it also applies to those English-language authors who are careful to avoid assuming knowledge of readers, for example, of the function of national bodies, such as the Quality Assurance Agency in the United Kingdom or the Association of American Colleges and Universities in the United States. 


\section{Selecting a title: Matters more than you might realize}

The title is the primary filter potential readers use to decide whether to look at the abstract and, then, possibly go on and read your piece. For most people, their awareness of your work is based on the titles of what you write, through journal and citation alerts, social media, searching Google Scholar or occasionally through browsing journal contents pages, and skimming the reference lists of publications that cite your work. Most people will not read beyond the title. So, your title has a big job to do: to encourage as many people as possible interested in your topic to read further. But we are not advocating misleading titles. While clever, eye-catching titles may attract some readers, the risk is that they may not attract the attention of the readers whom you would like to influence, including those who may later cite your work: "It could even be said, in the case of titles in the age of online publication, that boring and factual is good" (Thomson \& Kamler, 2013, p. 86).

One way to manage this dilemma is to use subtitles. The first part of the title could be eyecatching or identify the broad area addressed, for example, "By any other name?" (Healey, Lerczak, Welsh, \& France, 2019), or "Publish or perish" (Noble, 1989). But it is only when you read the subtitle that you learn about the specific focus of the articles and the contribution of the authors (in these two articles, they are, respectively, "The impacts of differing assumptions, expectations, and misconceptions on bringing about resistance to staff-student "partnerships"” and "What 23 journal editors have to say"). Hartley (2008) argues that the title "needs to stand out in some way from the other thousands of titles that compete for the reader's attention, but it also needs to tell the reader what the paper is about" (p. 23).

A title that might be appropriate for a teaching and learning journal in a discipline-for example, "Developing good educational practices: Lessons from geography"-needs revision for a crossdisciplinary journal focused on higher education. Indeed, Mick learned that it is usually best not to name the specific discipline in the title for a transdisciplinary audience. In 1998, when he used "geography" in the title of a presentation at Supporting Educational, Faculty and TA Development within Departments and Disciplines, his first cross-disciplinary international conference on higher education, no one came to the session. Why would they? None of them were geographers! The revised paper, "Developing the scholarship of teaching through the disciplines," was accepted for publication in Higher Education Research and Development (Healey, 2000) and has since been cited more than 450 times. Its success cannot, of course, be put down simply to changing the title, but the revised title has more potential to attract readers.

\section{Preparing the abstract: Planning and clarifying potential structure}

Along with the title, many more people will read the abstract than will read the rest of the article. (Note that abstracts are usually required for empirical research and conceptual articles, but not normally for reflective essays or opinion pieces.) Hence, your abstract should tell the story of your article. But it can also play other vital roles in the writing process, particularly as a planning device and as a final check on clarity.

Many people treat the abstract almost as an afterthought to dash off just before submitting their article, but it has far more generative uses. Preparing the first draft of the abstract before writing the article itself can clarify the argument, contribution, and structure of the article. This is how we planned this article, but the phrasing of the abstract went through several drafts as we wrote the article. Because 
writing is a creative process and will evolve as you go, you should use an initial abstract as a guide rather than a rigid framework. Alternatively, writing the abstract after writing the article can help you clarify whether you have made the argument you intended and prompt you to revise as needed. (You can use the abstract in this way for reflective essays and opinion pieces, even though you will not include the abstract with your submission.)

Thomson and Kamler (2013) describe the abstract as the "tiny text" that outlines and guides an article through a series of "moves." Drawing on Thomson and Kamler (2013), we illustrate these moves (table 1). We also offer, in text box 9, the abstract for this article with the "moves" identified (minus the "anchor" move, as a research design is not part of this article).

Table 1. Harnessing the abstract as a planning tool for an SoTL-focused publication

\begin{tabular}{|c|c|c|c|}
\hline MOVES & PURPOSE & QUESTIONS & SENTENCE STARTERS \\
\hline LOCATE & $\begin{array}{l}\text { Describe the broader } \\
\text { context within which } \\
\text { your study makes a } \\
\text { contribution. }\end{array}$ & $\begin{array}{l}\text { What is the broader topic of your } \\
\text { SoTL study? }\end{array}$ & $\begin{array}{l}{[\mathrm{xxx}] \text { is an issue of growing }} \\
\text { concern in universities. }\end{array}$ \\
\hline FOCUS & $\begin{array}{l}\text { State the issues, } \\
\text { questions, or } \\
\text { opportunities that your } \\
\text { study explores. }\end{array}$ & $\begin{array}{l}\text { How does your study explore this } \\
\text { broad topic more specifically? }\end{array}$ & $\begin{array}{l}\text { This study reports on research } \\
\text { into ... [conducted where and } \\
\text { with whom] to explore ... } \\
\text { [linked to above topic]. }\end{array}$ \\
\hline ANCHOR & $\begin{array}{l}\text { Articulate an overview of } \\
\text { your theoretical } \\
\text { framework and research } \\
\text { design. }\end{array}$ & $\begin{array}{l}\text { What literature, models, or } \\
\text { theories did you draw on? } \\
\text { How did you gather data? }\end{array}$ & $\begin{array}{l}\text { Our study was informed by }[\mathrm{xxx}] \\
\text { model/theory/ work. } \\
\text { The views of [specific study } \\
\text { participants] were captured } \\
\text { through ... }\end{array}$ \\
\hline REPORT & $\begin{array}{l}\text { Present the key findings } \\
\text { arising from your } \\
\text { research. }\end{array}$ & $\begin{array}{l}\text { What did you find overall from } \\
\text { the analysis of your study? }\end{array}$ & The results of our study were ... \\
\hline ARGUE & $\begin{array}{l}\text { Make an argument with } \\
\text { implications. }\end{array}$ & $\begin{array}{l}\text { What are you arguing as a result } \\
\text { of your research? } \\
\text { What are the implications arising } \\
\text { for SoTL broadly? }\end{array}$ & $\begin{array}{l}\text { We argue that ... } \\
\text { Our findings imply that... }\end{array}$ \\
\hline
\end{tabular}

\section{Text box 9: Abstract for this article with "moves" identified}

[LOCATE] There are many general books and articles on publishing in peer-reviewed journals, but few specifically address issues around writing for journals focused on the Scholarship of Teaching and Learning (SoTL). One of the challenges of beginning to write about teaching and learning is that most scholars have become interested in exploring these issues in higher education alongside their disciplinary interests and have 
to grapple with a new literature and sometimes unfamiliar methods and genres, as well. Hence, for many, as they write up their projects, they are simultaneously forging their identities as scholars of teaching and learning. [FOCUS] We discuss the process of producing four types of SoTL-focused writing for peerreviewed journals: empirical research articles, conceptual articles, reflective essays, and opinion pieces. Our goal is to support both new and experienced scholars of teaching and teaching-faculty/academics, professional staff, and students - as they nurture and further develop their voices and their identities as scholars of teaching and learning and strive to contribute to the enhancement of learning and teaching in higher education. [REPORT] We pose three related sets of overarching questions for consideration when writing about teaching and learning for peer-reviewed journals and offer heuristic frameworks for publishing in the four specific writing genres listed above. We also discuss how to get started with writing, preparing to submit, and responding to reviewers, focusing on the importance of contributing to and creating scholarly conversations about teaching and learning. [ARGUE] Finally, using the metaphor of being in conversation, we argue that writing is a values-based process that contributes to the identity formation of scholars of teaching and learning and their sense of belonging within the SoTL discourse community.

Since coming across this strategy in preparing this article, Mick and Kelly have become strong advocates of it as a way of planning a paper or a conference presentation, particularly when collaborating with others. On the other hand, Alison feels constrained by using such a structure in advance of writing and prefers not to use it. This difference highlights once again that there is not a "right way" to go about writing for a SoTL-focused publication.

\section{BEFORE AND AFTER: SUBMITTING THEN RESPONDING TO REVIEWERS}

Rewriting, revising, and refining make for good writing. In our collective, yet different, experiences, our first written draft has never become the published work. This is because writing is an iterative process. However, we observe (as editors and reviewers) that all too often our colleagues submit work before it is ready. We have been guilty of such premature submission ourselves because we get too close to our work. As a result, we struggle to see whether we are communicating our ideas effectively, what assumptions we are making regarding our readers' knowledge, what key points we have omitted, and, critically, where we could cut or precis.

We recommend, as is common in our own practice, asking one or more trusted colleagues to comment critically on a draft before submitting it. The final draft of this article benefitted considerably from the insights of eleven critical friends. Of course, we have established networks in the field to draw upon, and finding a critical friend can be daunting when you are new to the SoTL community. Sharing your work at local seminars or national or international conferences is a great way to connect with other scholars, who can in turn become critical friends who can help gauge how your work might be received prior to submitting for publication. Joining a writing group is another way to grow a network (Grant, 2016; Moore, 2018).

You should also ensure that your work meets the formatting, layout, and referencing style of the intended journal. As editors, we all know the frustration of receiving articles that appear to have been written for another journal. This signals that the submission is unlikely to be advancing the conversation of the journal and that the author has not paid close attention to the particular outlet to which it has been submitted. We comment on our own practices for finalizing our manuscripts (text box 10). 


\section{Text box 10: In our own words: Process for finalizing before submission}

Mick: I will not submit anything before asking several colleagues to comment on what I have written; in one 35,000 -word manuscript, I sent the draft to more than 20 colleagues. I found something to change as a result of each person's suggestions. Sometimes the comments I've received have led to a radical rethink and rewrite-most recently when my co-author and I received comments from Kelly and Alison (Healey \& Healey, 2018)!

Kelly: I only submit work that I believe is well formed and likely to be accepted after some revisions. I hold polished manuscripts for a week or two and then reread them. I typically seek critical friend review before submitting if something feels off that I cannot articulate clearly. I ensure that the work is polished and professional before submitting because I respect the collegial peer-review relationship.

Alison: It depends on the venue. If I feel confident that there will be collegial interactions and opportunities for revision, I might go ahead and send a piece without asking for colleagues' input and before it is totally polished because I know that the feedback I receive will help me shape it to fit the venue and its readers. I am not talking about sending in half-baked ideas or sloppy drafts; I am talking about being realistic that the paper will need to be revised and open to the feedback from reviewers. If I suspect that the venue will simply reject something that isn't totally polished, then I will ask several colleagues to read it over and try to get it to be the most polished it can be, although I still know that it is likely that reviewer feedback will reshape it.

Unconditional acceptances of submissions are extremely rare. Brookfield (2011) notes that in publishing more than 70 refereed journal articles over a 30-year period, only once was the verdict publish without revision. Minor or major revisions or rejection are much more common: "Minor revisions are, or ought to be, a cause for celebration" (Thomson \& Kamler, 2013, p. 128). It is important to be aware of these statistics as receiving what is perceived as negative feedback can trigger "a familiar cycle of emotions" (Brookfield, 2011, p. 252), which can shake the confidence of both new and experienced scholars of teaching and learning.

This emotional response may help explain why many authors struggle when responding to reviewers' feedback: up to 50 percent of revised and resubmitted manuscripts are rejected (Rynes et al., 2005). Many editors, on the other hand, are unconcerned by the emotional roller-coaster; what they are concerned with is how you respond to the review (Brookfield, 2011). You can help the editor here by including a table or list when you send in a revised manuscript specifying how you have responded to each of the reviewers' points - indeed, many journals require this. However, where you strongly disagree with a point it is quite acceptable to make a clearly argued case for why you think the recommendation is inappropriate. Sometimes it can be helpful to include a version of the paper using track changes, or a different colored font if the journal does not allow track changes, to highlight the alterations you have made to the original manuscript. Some journals ask for this, too.

Evoking the conversation metaphor again, we suggest that you approach the review process as a collegial exchange. While comments from reviewers might not always feel collegial, we prefer to give the benefit of the doubt to reviewers by remembering that they are busy yet took the time to engage in the peer-review process. Where reviewers seek revisions, we imagine the response as a collegial call to reshape our work so that it better contributes to a particular conversation. As such, we acknowledge all their comments, respond in turn, explicitly point to changes that have resulted from the review process, 
and express gratitude even when we argue against the suggested changes. However, where a review offends or crosses a line, you should contact the senior editor of the journal to discuss any inappropriate commentary.

\section{REFLECTIONS IN CONCLUSION}

Our intention in this article was to shed light on the process of writing SoTL articles for publication in peer-reviewed journals. In doing so, we have framed the specific advice we offered in terms of writing as identity development and the contribution to or creation of one or more conversations. We have also acknowledged the challenges and opportunities of integrating writing with one's identity as a scholar and positioning oneself among other scholars.

While, as we mentioned, we are wary of any claims of best-practice in relation to producing scholarly work about postsecondary teaching and learning for journals, we have argued for the importance of clarifying your own values and your chosen journal's mission and focus. We have also endeavored to articulate the qualities and criteria of the main forms of scholarly writing that are expected and accepted in journals publishing SoTL-focused work, and offered four heuristic frameworks to use as guides as you conceptualize, draft, and revise. In relation to the different writing genres, we have urged you to learn the conventions and to consider where you might push the boundaries- to evolve as a scholar in and through SoTL, and to help the field itself continue to evolve. We advocate exploration, experimentation, and enjoyment as much as structured intentionality.

We suggest that if you approach SoTL writing as contributing to and creating conversations with SoTL community members and engage in dialogue through writing articles, responding to reviews of your work, and reviewing others' work, this process of evolution will be both generative and engaging for all involved. We conclude with some thoughts from each of us (text box 11). We hear from some colleagues about forms of competition and exclusion in some disciplines that we hope the field of SoTL does not emulate. We cannot overstate the importance of networks of critical friends-individuals who can offer support, feedback, mentoring, and productive challenges as you develop and refine a voice and an identity (or voices and identities) within SoTL-focused conversations.

\section{Text box 11: In our own words: Concluding thoughts}

Mick: I've only recently learned that by drafting the abstract and title and choosing the journal we are going to submit to first, we've not only clarified the focus and argument of the article, but also saved a lot of time redrafting later. This does not mean that sometimes in the process of writing and reflecting and receiving comments from critical friends, all of these may not change radically, but it forces us to think clearly about what we are trying to contribute. It may not be for everyone, but it works for me, and it is how we set about planning this article.

Kelly: I've come to see writing as a conversation with the SoTL community-a dialogue through writing with respected peers. Thinking about whom I cite, the reviewers, readers, and editors as colleagues in conversation compels me to be critically kind. By critically kind I mean asserting my view and voice that typically challenges the status quo, yet in a way that acknowledges differing perspectives and views with the discourse community. For example, instead of attacking or dismissing work, I acknowledge it and offer a counter-view or alternative narrative. 
Alison: I continue to write about what matters to me and to others I work with, and that requires me to be open to process and collaboration. I enjoy responding to ideas that emerge in conversation with students, staff, and faculty colleagues and finding ways to situate and present them that will speak to others. Sometimes we start with a clear goal and message in mind and so can write the abstract first and clear paragraphs following; other times, we write toward what we want to say through a much messier, organic, longer, unpredictable process.

This discussion of writing about and for SoTL is one of many continuing conversations, and we in no way mean it to be the final word. Research - and other forms of scholarly writing - that builds on, complicates, revises, and extends these ideas will contribute to the further evolution of the field and the individual and collective scholars who comprise it. Stimulated by writing this article we are working on a book about writing in a range of genres about learning and teaching in higher education (Healey et al., in press). Finally, we should emphasize that although writing may be a challenge for many, it can also be a joyous and liberating experience, and once your work is published it provides an opportunity for welldeserved celebration.

\section{ACKNOWLEDGMENTS}

We are very grateful to Anita Acai, Sophia Abbot, Sally Brown, Peter Felten, Ruth Healey, Pat Hutchings, Nicola Simmons, Kathryn Sutherland, Helen Sword, and the anonymous reviewers for their insightful comments on earlier versions of this article. We also thank Ronald Barnett and Preeti Vayada for their feedback on our book manuscript, which, in turn, informed our final revisions of this article.

Mick Healey is a higher education consultant and an Emeritus Professor at the University of Gloucestershire (UK).

Kelly E Matthews is an Associate Professor in Higher Education at the University of Queensland (AUS).

Alison Cook-Sather is Mary Katharine Woodworth Professor of Education at Bryn Mawr College and Director of the Teaching and Learning Institute at Bryn Mawr and Haverford Colleges (USA).

\section{REFERENCES}

Belcher, W. L. (2009). Writing your journal articles in 12 weeks: A guide to academic publishing success. Thousand Islands, CA: Sage.

Bindra, G., Easwaran, K., Firasta, L., Hirsch, M., Kapoor, A., Sosnowski, A., Stec-Marksman, T., \& Vatansever, G. (2018). Increasing representation and equity in students as partners initiatives. International Journal for Students as Partners, 2(2), 10-15. https://doi.org/10.15173/ijsap.v2i2.3536

Black, D., Brown, S., Day, A., \& Race, P. (1998). 500 tips for getting published: A guide for educators, researchers and professionals. London: Kogan Page.

Boyer, E. L. (1990). Scholarship reconsidered: Priorities of the professoriate. Princeton, NJ: Carnegie Foundation for the Advancement of Teaching.

Brookfield, S. D. (2011). Addressing feedback from reviewers and editors. In T. S. Rocco, \& T. Hatcher (Eds.), The handbook of scholarly writing and publishing (pp. 251-261). San Francisco: Jossey-Bass.

Brost, C., Lauture, C., Smith, K., \& Kersten, S. (2018). Reflections on that-has-been: Snapshots from the studentsas-partners movement. International Journal for Students as Partners, 2(1), 130-135. https://doi.org/10.15173/ijsap.v2i1.3366

Chick, N. L., Cornell-Swanson, L. V., Lazarides, K., \& Meyers, R. (2014). Reconciling apples \& oranges: A constructivist SoTL writing program. International Journal for the Scholarship of Teaching and Learning, 8(2), Article 13. https://doi.org/10.20429/ijsotl.2014.080213 
Chick, N. \& Felten, P. (2018). How to tell a true SoTL story. In ISSOTL18 Toward a Learning Culture: Program and book of abstracts (p.193). Retrieved from https://portal.findresearcher.sdu.dk/files/144403358/ISSOTL18 program book.pdf

Chick, N., \& Poole, G. (2013). Launching TLI: SoTL's purposes, processes, and people. Editors' introduction. Teaching \& Learning Inquiry, 1(1), 1-4. https://doi.org/10.20343/teachlearninqu.1.1.1

Chick, N., \& Poole, G. (2018). Editors' introduction: In defense of microscopes. Teaching \& Learning Inquiry, 6(1), 1-2. https://doi.org/10.20343/teachlearninqu.6.1.1

Cook-Sather, A. (2015). Dialogue across differences of position, perspective, and identity: Reflective practice in/on a student-faculty pedagogical partnership program. Teachers College Record, 117(2). http://www.tcrecord.org/Content.asp?ContentlD=17784

Cook-Sather, A., Abbot, S., \& Felten, P. (2019). Legitimizing reflective writing in SoTL: "Dysfunctional illusions of rigor" revisited. Teaching \& Learning Inquiry, 7(2), 14-27. https://doi.org/10.20343/teachlearninqu.7.2.2

Day, A. (2016). How to get research published in journals. (2nd ed.). Abingdon: Routledge.

Felten, P. (2013). Principles of good practice in SoTL. Teaching \& Learning Inquiry, 1(1), 121-125. https://doi.org/10.20343/teachlearninqu.1.1.121

Fisher, R., Ross, B., LaFerriere, R., \& Maritz, A. (2017). Flipped learning, flipped satisfaction, getting the balance right. Teaching \& Learning Inquiry, 5(2), 114-127. https://doi.org/10.20343/teachlearninqu.5.2.9.

Goldsmith, M., Hanscom, M., Throop, S., \& Young, C. (2017). Growing student-faculty partnerships at Ursinus College: A brief history in dialogue. International Journal for Students as Partners, 1(2). https://doi.org/10.15173/ijsap.v1i2.3075

Grant, B. M. (2016). Getting my work out there: Writing the journal article. In C. Sugrue, \& S. Mertkan (Eds.), Publishing and the academic world: Passion, purpose and possible futures (pp. 75-89). London: Routledge.

Hartley, J. (2008). Academic writing and publishing: A practical handbook. London: Routledge.

Healey, M. (2000). Developing the scholarship of teaching through the disciplines. Higher Education Research and Development, 19(2), 169-189. https://doi.org/10.1080/072943600445637

Healey, M. (2003). The scholarship of teaching: Issues around an evolving concept. Journal on Excellence in College Teaching, 14(2/3), 5-26. Retrieved from http://celt.miamioh.edu/ject/issue.php?v=14\&n=2\%20and\%203

Healey, M. (2017). Reflections on the development of International Collaborative Writing Groups (ICWGs) about teaching and learning in higher education. Canadian Journal for the Scholarship of Teaching and Learning, 8(3). Article 3 https://doi.org/10.5206/cjsotl-rcacea.2017.2.3

Healey, M., \& Healey, R. L. (2018). "It depends": Exploring the context-dependent nature of students as partners practices and policies. International Journal for Students as Partners, 2(1). https://doi.org/10.15173/ijsap.v2i1.3472

Healey, M., \& Jenkins, A. (2003). Discipline-based educational development. In H. Eggins, \& R. Macdonald (Eds.), The scholarship of academic development (pp. 47-57). Buckingham: Open University Press.

Healey, M., Matthews, K.E., \& Cook-Sather, A. (in press). Writing about learning and teaching in higher education: Creating and contributing to public scholarly conversations across a range of genres. Elon, NC: Elon University Center for Engaged Learning Open-Access Books.

Healey, R. L., Lerczak, A., Welsh, K., \& France, D. (2019). By any other name? The impacts of differing assumptions, expectations, and misconceptions in bringing about resistance to staff-student "partnerships." International Journal for Students as Partners, 3(1), 106-122. https://doi.org/10.15173/ijsap.v3i1.3550

Huber, M. T. and Hutchings, P. (2005). The advancement of learning: Building the Teaching Commons. San Francisco, CA: Jossey-Bass.

Johnstone, K., Marquis, E., \& Puri, V. (2018). Public pedagogy and representations of higher education in popular film: New ground for the scholarship of teaching and learning. Teaching \& Learning Inquiry, 6(1), 25-37. https://doi.org/10.20343/teachlearninqu.6.1.4

Kamler, B., \& Thomson, P. (2014). Helping doctoral students write: Pedagogies for supervision. (2nd ed.). London: Routledge.

Kinash, S., \& Wood, K. (2012). Workshop on "research questions" (personal communication).

Kreber, C. (2013). The transformative potential of the scholarship of teaching. Teaching and Learning Inquiry, 1(1), 5-18. https://doi.org/10.2979/teachlearninqu.1.1.5 
Little, D., Green, D. A., \& Hoption, C. (2018). A lasting impression: The influence of prior disciplines on educational developers' research. International Journal for Academic Development, 23(4), 324-338. https://doi.org/10.1080/1360144X.2018.1458617

Macfarlane, K., Dennison, J., Delly, P., \& Mitric, D. (2018). Sailing through a storm: The importance of dialogue in student partnerships. International Journal for Students as Partners, 2(2), 144-150. https://doi.org/10.15173/ijsap.v2i2.3457

Martin, E., Benjamin, J., Prosser, M. \& Trigwell, K. (1999). Scholarship of teaching: A study of the approaches of academic staff. In C. Rust (Ed.), Improving student learning: Improving student learning outcomes (pp. 326331). Oxford: Oxford Centre for Staff and Learning Development, Oxford Brookes University.

Matthews, K. E. (2018a). Simple publication pro forma: A heuristic framework to shape an empirical publication. Brisbane: University of Queensland. Retrieved from https://espace.library.uq.edu.au/view/UQ:68aebe0

Matthews, K. E. (2018b). Publication pro forma: A heuristic framework to support scholarly research into teaching and learning. Brisbane: University of Queensland. Retrieved from https://espace.library.uq.edu.au/view/UQ:2f9b305

Matthews, K. E., Marquis, E., \& Healey, M. (2017). International collaborative writing groups as communities of practice. In J. McDonald \& A. Cater-Steel (Eds.), Implementing communities of practice in higher education: Dreamers and schemers (pp. 597-617). Singapore: Springer.

Maurer, T. (2017). Guidelines for authorship credit, order, and co-inquirer learning in collaborative facultystudent SoTL projects. Teaching \& Learning Inquiry, 5(1), 1-17. http://dx.doi.org/10.20343/teachlearninqu.5.1.9

McDonald, F., Reynolds, J., Bixley, A., \& Spronken-Smith, R. (2017). Changes in approaches to learning over three years of university undergraduate study. Teaching \& Learning Inquiry, 5(2), 65-79. https://doi.org/10.20343/teachlearninqu.5.2.6

Miller-Young, J. E., Yeo, M., \& Manarin, K. (2018). Challenges to disciplinary knowing and identity: Experiences of scholars in a SoTL development program. International Journal for the Scholarship of Teaching and Learning, 12(1), Article 3. https://doi.org/10.20429/ijsotl.2018.120103

Moore, J. L. (2018). Writing SoTL: Going public for an extended audience. In N. L. Chick (Ed.), SoTL in action: Illuminating critical moments of practice (pp. 119-126). Sterling, VA: Stylus.

Murray, R. (2009). Writing for academic journals. (2nd ed.). Maidenhead: Open University Press.

Nevin, A. I., Thousand, J. S., \& Villa, R. A. (2011). Working with coauthors. In T. S. Rocco, \& T. E. Hatcher (Eds.), The handbook of scholarly writing and publishing (pp. 274-292). San Francisco: Jossey-Bass.

Noble, K. (1989). Publish or perish: What 23 journal editors have to say. Studies in Higher Education, 14(1), 97-102. https://doi.org/10.1080/03075078912331377642

O'Shea, S. (2018). Equity and students as partners: The importance of inclusive relationships. International Journal for Students as Partners, 2(2), 16-20. https://doi.org/10.15173/ijsap.v2i2.3628

Poole, G. (2013). Square one: What is research? In K. McKinney (Ed.), The scholarship of teaching and learning in and across the disciplines (pp. 135-151). Bloomington, IN: Indiana University Press.

Rocco, T. S., \& Hatcher, T. (Eds.) (2011). The handbook of scholarly writing and publishing. San Francisco, CA: JosseyBass.

Rynes, S. L., Hillman, A., Ireland, R. D., Kirkman, B. L. Law, K. S., Miller, C. C., Rajagopalan, N., \& Shapiro, D. (2005). Everything you've always wanted to know about $A M J$ (but may have been afraid to ask). Academy of Management Journal, 48(5), 732-737. https://doi.org/10.5465/amj.2005.28563879

Sadler, R. (2006). Up the publication road: A guide to publishing in scholarly journals for academics, researchers and graduate students. (3rd ed.). Milperra, NSW: Higher Education Research and Development Society of Australasia.

Shulman, L. S. (1999). Taking learning seriously. Change, 31(4), 10-17. https://doi.org/10.1080/00091389909602695

Simmons, N., Abrahamson, E., Deshler, J. M., Kensington-Miller, B., Manarin, K., Morón-García, S., Oliver, C., \& Renc-Roe, J. (2013). Conflicts and configurations in a liminal space: SoTL scholars' identity development. Teaching \& Learning Inquiry, 1(2), 9-21. https://doi.org/10.20343/teachlearninqu.1.2.9

Sword, H. (2012). Stylish academic writing. Cambridge, MA: Harvard University Press. 
Sword, H. (2016). "Write every day!" A mantra dismantled. International Journal for Academic Development, 21(4), 312-322. https://doi.org/10.1080/1360144X.2016.1210153

Teaching and Learning Inquiry [TLI] (n.d.) Focus and scope. Retrieved from https://journalhosting.ucalgary.ca/index.php/TLI/about\#focus

Thomson, P. (2017). "Internationalising" a journal article. [Web log post] Retrieved from https://patthomson.net/2017/10/09/internationalising-a-journal-article/

Thomson, P., \& Kamler, B. (2013). Writing for peer reviewed journals: Strategies for getting published. London: Routledge.

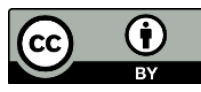

Copyright for the content of articles published in Teaching \& Learning Inquiry resides with the authors, and copyright for the publication layout resides with the journal. These copyright holders have agreed that this article should be available on open access under a Creative Commons Attribution License 4.0 International (https://creativecommons.org/licenses/by/4.0). The only constraint on reproduction and distribution, and the only role for copyright in this domain, should be to give authors control over the integrity of their work and the right to be properly acknowledged and cited, and to cite Teaching \& Learning Inquiry as the original place of publication. Readers are free to share these materials - as long as appropriate credit is given, a link to the license is provided, and any changes are indicated. 